(C) The Author(s), 2021. Published by Cambridge University Press for the Arizona Board of Regents on behalf of the University of Arizona. This is an Open Access article, distributed under the terms of the Creative Commons Attribution licence (https://creativecommons.org/licenses/by/4.0/), which permits unrestricted re-use, distribution, and reproduction in any medium, provided the original work is properly cited.

\title{
EVIDENCE OF MASS MORTALITY OF THE LONG-LIVED BIVALVE MERCENARIA STIMPSONI CAUSED BY A CATASTROPHIC TSUNAMI
}

\author{
Kaoru Kubota ${ }^{1,2,3 *}$ (D) Kotaro Shirai ${ }^{2} \cdot$ Naoko Murakami-Sugihara $^{2} \cdot$ Koji Seike $^{4}$ • \\ Masayo Minami ${ }^{3} \cdot$ Toshio Nakamura ${ }^{3} \cdot$ Kazushige Tanabe ${ }^{5}$ \\ ${ }^{1}$ Graduate School of Human Development and Environment, Kobe University, 3-11 Tsurukabuto, Nada-ku, Kobe, \\ Hyogo 657-8501, Japan \\ ${ }^{2}$ Atmosphere and Ocean Research Institute, The University of Tokyo, 5-1-5 Kashiwanoha, Chiba 277-8564, Japan \\ ${ }^{3}$ Institute for Space-Earth Environmental Research, Nagoya University, Furo-cho, Nagoya, Aichi 464-8601, Japan \\ ${ }^{4}$ Geological Survey of Japan, National Institute of Advanced Industrial Science and Technology, 1-1-1 Higashi, \\ Tsukuba, Ibaraki 305-8567, Japan \\ ${ }^{5}$ University Museum, The University of Tokyo, 7-3-1 Hongo, Bunkyo-ku, Tokyo 113-8654, Japan
}

\begin{abstract}
Tsunamis are huge disasters that can significantly damage benthic organisms and the sea-bottom environment in coastal areas. It is of great ecological importance to understand how benthic ecosystems respond to such destructive forces and how individual species are affected. Investigating the effect of such disasters on animals that are seldom caught alive is particularly difficult. Bivalve mollusks are especially suitable for investigating how a tsunami affects coastal benthic species because they preserve an environmental record in their shells that can be extended back in time by crossdating the records of multiple individuals. Here we studied dead shells of Mercenaria stimpsoni, a longlived clam, and precisely determined the time of death by using nuclear bomb-induced radiocarbon (bomb- ${ }^{14} \mathrm{C}$ ) and by counting annual growth increments. First, a quasi-continuous, regional bomb- ${ }^{14} \mathrm{C}$ record was created by analyzing the shells of 6 live-caught $M$. stimpsoni individuals. Then 27 dead shells collected from the seafloor of Funakoshi Bay were ${ }^{14} \mathrm{C}$-dated and analyzed. The results showed that the huge tsunami that struck northeastern Japan on 11 March 2011 caused mass mortality of this bivalve in Funakoshi Bay. Nine of the 27 clams died during the March 2011 tsunami, probably by starvation after burial by tsunami deposits or exposure above the seafloor as a result of sediment liquefaction during the earthquake. The dating method used in this study can help us understand how long-lived marine organisms with low population density are affected by huge natural disasters such as a tsunami.
\end{abstract}

KEYWORDS: bivalve, Mercenaria stimpsoni, radiocarbon, sclerochronology, tsunami.

\section{INTRODUCTION}

Natural disasters such as tsunamis, earthquakes, typhoons, and volcanic ash falls can substantially disturb benthic ecosystems in coastal areas (López et al. 2008; Jaramillo et al. 2012; Seike et al. 2013; Harris 2014). In particular, tsunamis can cause either rapid sedimentation, thus burying benthic organisms deep under the seafloor, or rapid erosion, thus washing them out of the upper layer of substrate and exposing them to predation (Kranz 1974; Bromley 1996; López et al. 2008). On 11 March 2011, the Tohoku-Oki Earthquake, a M9.0 megathrust earthquake, ruptured the plate boundary off the Pacific coast of northeastern Japan (Ide et al. 2011) and generated a huge tsunami that affected $2000 \mathrm{~km}$ of the Pacific coast of northeastern Japan (Mori et al. 2011). In Funakoshi Bay, Iwate prefecture, the tsunami run-up height was $29.4 \mathrm{~m}$ (Ishimura and Yamada 2019), and largescale seafloor erosion and sedimentation occurred, followed by the re-establishment of bioturbation (Seike et al. 2016, 2017, 2018, 2019). Furthermore, population densities of sand dollar Scaphechinus mirabilis (an echinoid) and Sakhalin surf clam Pseudocardium sachalinense (a mollusk) in the bay were significantly decreased by the tsunami disturbance (Seike et al. 2013). Although investigating the population dynamics of animals with a large population density before (and after) the tsunami is possible if the data from before the event are available, investigating those with a small population density and rare catch opportunity

*Corresponding author. Email: kaoryu0129@gmail.com 
is extremely difficult. In addition, in most coastal areas, environmental or ecosystem survey records from before an event are unlikely to be available; as a result, it is usually very difficult or even impossible to assess the effect of a catastrophic event on coastal ecosystems. Some marine animals such as mollusks have a countinuously grown calcium carbonate shell. As a result, mollusk shells continuously record the ambient environment, making them excellent archives of past environments and environmental disturbances (e.g., MurakamiSugihara et al. 2019). The cold-water venerid bivalve Mercenaria stimpsoni (Stimpson's hard clam), which lives in Funakoshi Bay, is a long-lived mollusk with a shell that displays distinct annual growth increments (Kubota et al. 2017, 2018a; Shirai et al. 2018). It is thus possible to test the response of this marine mollusk to environmental perturbation, despite its low population density in the bay (Seike et al. 2013), because gaps in the shell record can be filled by using crossdating to combine the records of multiple individuals.

Mercenaria stimpsoni is the most long-lived among modern bivalves living near the Japanese coast (Shirai et al. 2018), and its shell growth pattern and the paleoenvironmental implications of the pattern have been documented previously (Tanabe et al. 2017; Kubota et al. 2017, 2018a; Shirai et al. 2018). This species inhabits fine sandy substrata in the shallow coastal zone (water depth 5-30 m) along mid- to high-latitude coasts of the northwest Pacific, the Sea of Japan, and the Sea of Okhotsk (Habe 1977). It is an infaunal filter feeder that consumes phytoplankton (predominantly diatoms) and suspended organic matter (Kubota et al. 2017; Seike et al. 2017). At ontogenetically younger stages $(<15$ years old), the shells grow from early spring to late summer at a relatively high rate $(\sim 10 \mathrm{~mm} / \mathrm{yr})$, but shell growth ceases or is substantially reduced during winter, when the water temperature is below $\sim 10^{\circ} \mathrm{C}$ (Kubota et al. 2017). At ontogenetically older stages (>15 years), shell growth occurs only in summer and the growth rate is very low $(0.05-0.1 \mathrm{~mm} / \mathrm{yr})$. Growth cessation lines are visible in shell cross sections, and the calendar year of past growth increments of a live-caught clam can be obtained by counting the annual growth lines backward from the most recent (Kubota et al. 2018a; Shirai et al. 2018).

Many dead M. stimpsoni shells can be found on the seafloor of Funakoshi Bay. While a modern specimen provides a record that extends back to when the specimen first developed a shell, by combining, through crossdating (e.g., Black et al. 2016), the annual growth increment records of modern specimens with those of specimens that lived during an earlier period, the paleoenvironmental record can be extended further back in time to produce a master chronology. However, to obtain a continuous record with annual resolution, we need to determine the dates of death of dead shells very precisely, with a precision of one year. However, crossdating of dead shells is more complicated than crossdating of live-caught specimens because the record of a dead shell, especially if it is short, may match several calendar year intervals in the master chronology. Conventional radiocarbon dating of marine samples has a large age determination error of more than \pm 50 years, which stems from the analytical precision and uncertainties of the seawater ${ }^{14} \mathrm{C}$ calibration curve (e.g., Marine20, Heaton et al. 2020) and the marine ${ }^{14} \mathrm{C}$ reservoir age (Alves et al. 2018). One way to overcome this problem is to use ${ }^{14} \mathrm{C}$ produced by atomic bomb testing (Hua et al. 2013). Intense atmospheric testing of thermonuclear weapons conducted in the $1950 \mathrm{~s}$ and 1960s artificially produced ${ }^{14} \mathrm{C}$ through reactions of high-energy neutrons with atmospheric nitrogen (bomb- ${ }^{14} \mathrm{C}$ ). The bomb- ${ }^{14} \mathrm{C}$ entered the Earth surface system and has already been widely used as a tracer for studying biogeochemical cycles and to estimate the longevity of both terrestrial and marine organisms (Kalish 1993; Campana et al. 2002; Hamady et al. 2014; Nielsen et al. 2016). 
Although mixing occurs rapidly in the atmosphere, in seawater mixing occurs more slowly; as a result, bomb- ${ }^{14} \mathrm{C}$ is heterogeneously distributed in the surface of the ocean (Mahadevan 2001; Druffel 2002; Grottoli and Eakin 2007; Scourse et al. 2012; Toggweiler et al. 2019). Therefore, to use the bomb- ${ }^{14} \mathrm{C}$ record as an age-determination tool, a continuous regional bomb- ${ }^{14} \mathrm{C}$ record must first be established. Kubota et al. (2018a) established a bomb- ${ }^{14} \mathrm{C}$ record for Funakoshi Bay by crossdating the 6 live-caught $M$. stimpsoni individuals mentioned above (this study improved the curve by adding 4 new data points; see Online Supplementary Material).

In the present study, we used crossdating and the bomb- ${ }^{14} \mathrm{C}$ record to determine the precise (annually resolved) ages of dead shells of $M$. stimpsoni collected from the seafloor of Funakoshi Bay. We then compared our analysis results with the timing and amplitude of past tsunamis to determine how they might have affected the mortality of this species in the bay. We also measured the ${ }^{14} \mathrm{C}$ content of an articulated $M$. stimpsoni shell found in a marine sediment core obtained from tsunami deposits in Funakoshi Bay in 2014. The goal of this study is to assess how past tsunamis, especially one occurred at 11 March 2011, affected the mortality of M. stimpsoni in Funakoshi Bay.

\section{METHODS}

Funakoshi Bay is located on a ria coast, a part of the Sanriku coast of northeastern Japan (Figure 1). The coastal plain along this section of coast is narrow, and the bay, which faces the open ocean, is directly affected by ocean wave activity. The floor of the bay is covered by poorly sorted sand and inclines gradually toward the open ocean (Seike et al. 2013). Otsuchi Bay is a rectangular bay, located immediately south of Funakoshi Bay, that measures $8 \mathrm{~km}$ from east to west and $2 \mathrm{~km}$ from north to south (Figure 1). Water depth increases gradually toward the bay mouth, where it reaches $70 \mathrm{~m}$. Otsuchi Bay is fed by three main rivers (the Otsuchi, Kozuchi, and Unosumai Rivers). Each river discharges freshwater in the bay at a rate of $3-10 \mathrm{~m}^{3} / \mathrm{s}$ (Kubota et al. 2018b).

In this study, we used 5 live M. stimpsoni specimens collected from the seafloor of Funakoshi Bay (site F-1, 20 m water depth; Figure 1) and 1 from Otsuchi Bay (site O-3, 5 m water depth) during a dive or by using a Smith-McIntyre mud sampler (see Online Supplementary Material) (Kubota et al. 2018a). These specimens were frozen after recovery and then transported to the laboratory for the removal of their soft tissues. In the laboratory, the shells were cleaned and dried at room temperature. We also collected both the right and left valves of dead shells (in rare cases articulate shells, too) of $M$. stimpsoni from the seafloor at site F-1 in Funakoshi Bay (Figure 1) during SCUBA dives. We selected 27 right valves of the dead shells for further analysis to avoid duplication of the analysis in the same individuals.

For the analysis we also used one articulated $M$. stimpsoni specimen (see Online Supplementary Material) that was removed from a sediment core $(6 \mathrm{~cm}$ in diameter, $100 \mathrm{~cm}$ long) collected from the seafloor of Funakoshi Bay (F-1) in September 2014 (Seike et al. 2017). The removed M. stimpsoni specimen was stored in a plastic bag until analysis. Sedimentary structures preserved in the core have already been reported in Seike et al. (2017). Briefly, the structures were examined by using a computed tomography (CT) scanner (LightSpeed Ultra16, GE Healthcare Japan Corp.) at the Center for Advanced Marine Core Research, Kochi University, Kochi, Japan. To observe both physical and biogenic sedimentary structures in the core, the CT scans were visualized by using OsiriX imaging software 
(A)

(B)
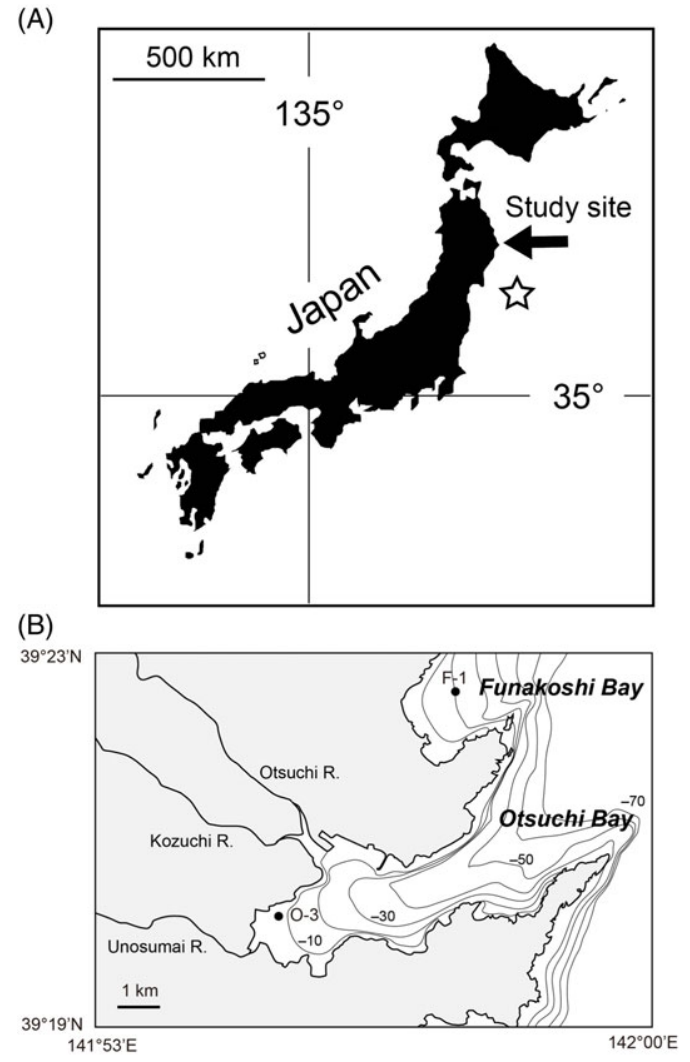

Figure 1 (A) Location of study site. The star indicates the epicenter of the 2011 Tohoku-oki earthquake. (B) Bathymetric map of Funakoshi Bay and Otsuchi Bay (bathymetric contour interval, $10 \mathrm{~m}$ ), modified from Kubota et al. (2018a). Shells and seawater were sampled at location F-1 in Funakoshi Bay and at location O-3 in Otsuchi Bay.

(version 4.1.2). After the core was scanned, it was sliced into 5-cm-long subsamples for analysis of the grain-size distribution with a laser granulometer (Mastersizer 2000, Malvern Instruments) at the Center for Advanced Marine Core Research.

The preparation of the live specimens for sclerochronological analysis was described by Kubota et al. (2018a), and the dead shells were prepared following the same method. First, we carefully removed materials adhering to the dead shell surfaces using a brush and then dried the shells at room temperature. From the 27 individuals, we selected 22 with relatively thick shells (i.e., with greater longevity), because short-lived individuals are not suitable for sclerochronological analysis. Then, each valve was wrapped in epoxy resin and sectioned from the umbo to the ventral margin along the maximum growth axis with a low-speed saw (Buehler Isomet). A cross-section was prepared and polished, and then images of the section were taken at 100 $\times$ magnification with a KEYENCE digital microscope.

On the photographic image of each cross section, we counted the number of annual increments and measured their width by using ImageJ freeware (http://imagej.nih.gov/ij/). Growth in $M$. stimpsoni is similar to growth in trees in that growth increments vary in width and show strong 
ontogenetic trends (Tanabe et al. 2017; Kubota et al. 2017; Shirai et al. 2018). We used the ARSTAN software package (https://www.ldeo.columbia.edu/tree-ring-laboratory/resources/ software), following Butler et al. (2009a, 2009b), to produce a chronology by detrending and standardizing the time series data on annual growth increment widths. A negative exponential function was fitted to the time series of annual growth increment widths and then the residuals from the fitted function were calculated. We used the following equation to calculate the growth index (GI) for each year for each shell:

$$
\mathrm{GI}=\frac{\mathrm{m}_{\mathrm{t}}}{\mathrm{p}_{\mathrm{t}}}
$$

where $m_{t}$ is the measured annual increment width, and $p_{t}$ is the annual increment predicted from the fitted curve, at age $t$. Annual increment width records of modern shells has already been reported in Kubota et al. (2018a), but those of dead shell are reported in this study for the first time. Then we calculated the standardized shell growth index (SGI; Jones et al. 1989) from the GI:

$$
\mathrm{SGI}=\frac{\left(\mathrm{GI}-\mathrm{x}_{\mathrm{GI}}\right)}{\mathrm{s}_{\mathrm{GI}}}
$$

where $x$ is the average and $\sigma$ is the standard deviation of all GI values of the time series. The SGI is a dimensionless measure of shell growth that can be used for direct comparisons of shell growth between different specimens and different ontogenetic stages. According to Black et al. (2016), we visually crossdated both the live-caught and dead shells to produce a master chronology for the study area. We also calculated the expressed population signal (EPS) to evaluate the strength of the correlations among the individual time series and between those time series and the master chronology (Wigley et al. 1984). Window length was set to 10 years in this exercise.

In this study, we used the time series data of annual growth increment widths for the shells of the 6 live-caught clams reported by Kubota et al. (2018a), together with data from 15 dead shells (among the $27{ }^{14} \mathrm{C}$-dated dead shells), reported here for the first time. In 22 dead shells that were sclerochronologicaly analyzed 7 showed little annual variation and was not able to obtain dates, thus we did not include them in the master chronology. A cross section of the articulated M. stimpsoni specimen was not made because the shell was broken during coring (see Online Supplementary Material).

To obtain the most recent record from each shell, we traced the surface of the last-precipitated portion of the shell (last increment; see Online Supplementary Material) with a grinder to remove surface contamination and then collected calcium carbonate powder from the fresh surface. We also sampled the articulated M. stimpsoni from the sediment core in this manner.

We first photographed each cross section. Then we used a high-precision micromilling system (Geomill326, Izumo Web, Japan) and a triangular tungsten carbide drill bit (Shofu) and drilled into the outer shell layer to obtain samples of the annual growth layers for ${ }^{14} \mathrm{C}$ analysis (e.g., Kubota et al. 2015a, 2015b, 2017; Sakamoto et al. 2017). By centering the drilling path on a relatively wide annual growth increment (length $\sim 10 \mathrm{~mm}$, width $0.8 \mathrm{~mm}$, depth $1.4 \mathrm{~mm}$ ), $10-15$ $\mathrm{mg}$ of calcium carbonate powder was obtained (see Online Supplementary Material). After drilling, we examined the drilled cross section to estimate the period of time-averaging and 
the mean number of years represented by each powder sample (see Online Supplementary Material).

Most of the radiocarbon analysis results for the live-caught shells (20 of $24{ }^{14} \mathrm{C}$ data points) have already been reported by Kubota et al. (2018a), but all radiocarbon data of dead shells are reported here for the first time. Five calcium carbonate powder samples were submitted to Paleo Labo Co. Ltd., Gifu, Japan, for routine ${ }^{14} \mathrm{C}$ analysis with a compact accelerator mass spectrometer (AMS; NEC, USA). Other calcium carbonate powder samples were reacted with phosphoric acid, and the carbon dioxide produced was converted to graphite by a Fe catalyst at $620^{\circ} \mathrm{C}$ for $6-12 \mathrm{hr}$. The target graphite samples were measured with a Tandetron AMS (High Voltage Engineering Europa, the Netherlands) installed at the Institute for Space-Earth Environmental Research, Nagoya University.

The ${ }^{14} \mathrm{C}$ measurements are expressed as the fraction of modern ${ }^{14} \mathrm{C}, \mathrm{F}^{14} \mathrm{C}$, calculated with the following equation:

$$
\mathrm{F}^{14} \mathrm{C}=\frac{\mathrm{A}_{\mathrm{SN}}}{\mathrm{A}_{\mathrm{ON}}}
$$

where $\mathrm{A}_{\mathrm{SN}}$ and $\mathrm{A}_{\mathrm{ON}}$ are the ${ }^{14} \mathrm{C} /{ }^{12} \mathrm{C}$ ratios of the sample and of the NIST oxalic acid standard (HOxII), respectively, normalized to $\delta^{13} \mathrm{C}_{\mathrm{PDB}}=-25 \%$. The error of the $\mathrm{F}^{14} \mathrm{C}$ analysis by Paleo Labo was better than 0.0026 ( $1 \sigma$; see Online Supplementary Material). The error of the $\mathrm{F}^{14} \mathrm{C}$ analysis at Nagoya University was better than $0.0040(1 \sigma)$, except for two samples $(0.0070$ and 0.0068) with low beam intensities (see Online Supplementary Material).

The time averaging of the samples drilled from the live-caught specimens was 1-7 years, but in half of the samples, high-resolution sampling of $<2$ years was achieved (see Online Supplementary Material). We previously confirmed that ${ }^{14} \mathrm{C}$ of the last increment of livecaught individuals represents that of dissolved inorganic carbon in the seawater (for details, see Kubota et al. 2018a). For samples that died in the pre-bomb era, conventional ${ }^{14} \mathrm{C}$ ages were converted to calendar ages before $1950 \mathrm{CE}$ by using the Marine20 calibration curve (Heaton et al. 2020) and the local marine ${ }^{14} \mathrm{C}$ reservoir age of $-49 \pm 20{ }^{14} \mathrm{C} \mathrm{yr}$, which was calculated by using $7{ }^{14} \mathrm{C}$ measurements of the pre-bomb era portion of live-caught individuals (Alves et al. 2018) (see Online Supplementary Material).

\section{RESULTS}

The present study added 4 new ${ }^{14} \mathrm{C}$ data points to the bomb- ${ }^{14} \mathrm{C}$ record for Funakoshi Bay established by Kubota et al. (2018a). The expanded record improves the time resolution of the period from 1953 to 1963 . We also merged radiocarbon data (6 data points) from the live-caught $M$. stimpsoni shell from Otsuchi Bay (specimen 120901OTW_alive), which is immediately south of Funakoshi Bay (Figure 1), with the bomb- ${ }^{14} \mathrm{C}$ record for Funakoshi Bay, because there is no discernible difference in seawater and shell $\mathrm{F}^{14} \mathrm{C}$ values between the two bays (for more details, see Kubota et al. 2018a). One likely reason of similar ${ }^{14} \mathrm{C}$ content irrespective of river water input is that freshwater run away at the very surface $(0-3 \mathrm{~m})$ of the Otsuchi Bay. (e.g., Tanaka et al. 2017). In the refined bomb- ${ }^{14} \mathrm{C}$ record, the last appearance of pre-bomb ${ }^{14} \mathrm{C}$ is in 1955 (in the previous record, it is 1952). 

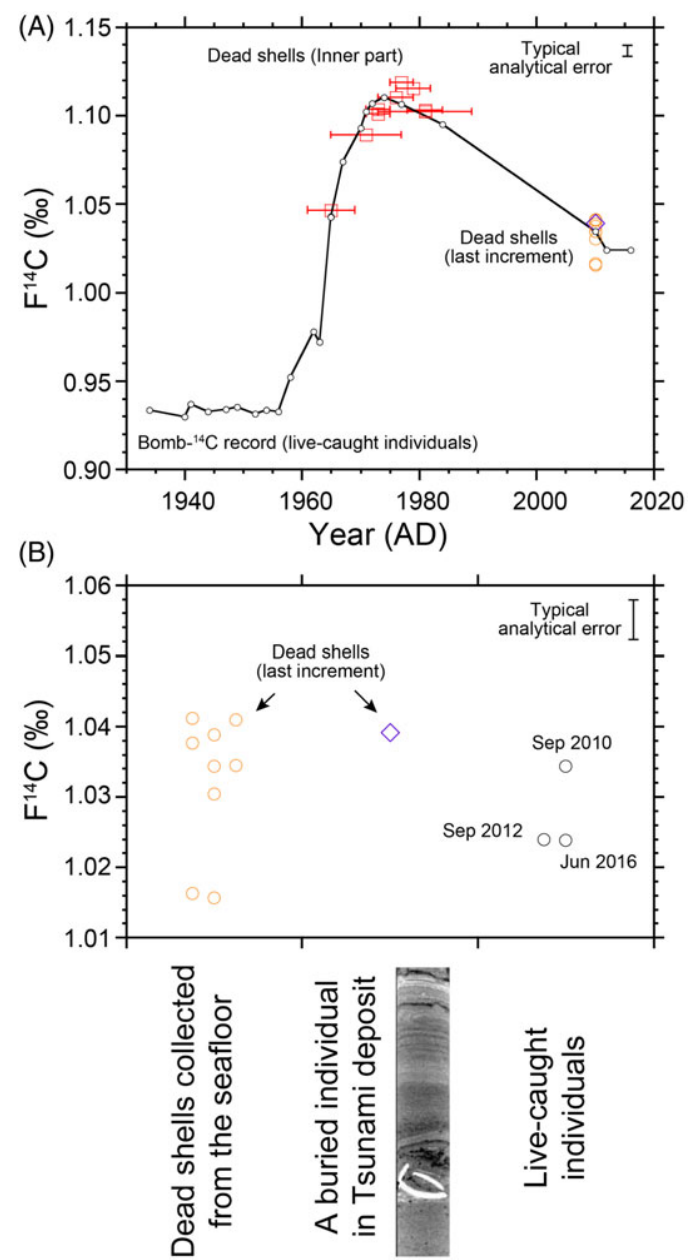

Figure 2 (A) Bomb- ${ }^{14} \mathrm{C}$ record of the study area that was created by using 6 live-caught individuals (black line with circles) (Kubota et al. 2018a). The $\mathrm{F}^{14} \mathrm{C}$ values of the last increment (yellow circles) and inner parts (red squares) of the shells of clams that were likely killed by the March 2011 tsunami are also shown. The horizontal error bars of the red squares represent the period of time averaging, not the dating uncertainty. (B) From left to right: $\mathrm{F}^{14} \mathrm{C}$ values of the last increments of shells of clams that were likely killed by the March 2011 tsunami (yellow circles), a buried articulate dead shell found within the tsunami deposits (purple diamond), and live-caught individuals (black circles), together with the dates on which they were collected.

In the refined bomb- ${ }^{14} \mathrm{C}$ record $\mathrm{F}^{14} \mathrm{C}$ value is approximately constant at about 0.9333 until 1956 (Figure 2), and then it increases rapidly until 1974 to a peak of 1.1102. After this peak, $\mathrm{F}^{14} \mathrm{C}$ values gradually decrease, to $1.0238 \pm 0.0027$ in 2012 and to $1.0239 \pm 0.0024$ in 2016. These values are in good agreement with $\mathrm{F}^{14} \mathrm{C}$ values of dissolved inorganic carbon of the in-situ seawater $(1.0263 \pm 0.0066, \mathrm{~N}=10)$, indicating that the shells directly record seawater ${ }^{14} \mathrm{C}$ (Kubota et al. 2018a). Furthermore, these values are almost identical to the average $\mathrm{F}^{14} \mathrm{C}$ value of atmospheric $\mathrm{CO}_{2}(1.0256 \pm 0.0078, \mathrm{~N}=59$ for 2012-2016, based on monthly observations at Schauinsland, Germany, by Heidelberg University: Hammer and Levin 2017). The peak value of 1.1102 corresponds to $70 \%$ of the peak value of surface water in the North Pacific subtropical gyre (the highest seawater value) and to $11 \%$ of the 
peak atmospheric value (e.g., Konishi et al. 1981; Fallon and Guilderson 2008; Glynn et al. 2013; Andrews et al. 2016; Hirabayashi et al. 2017). Given that the estimation error of $\mathrm{F}^{14} \mathrm{C}$ is about 0.0030 , the bomb- ${ }^{14} \mathrm{C}$ peak is strong enough to be used for age determination of the dead shells.

We found that the correlation between an average of standardized shell growth indexes (SGI) of the 6 live-caught individuals and the SGIs of 10 dead shells was statistically significant in all combinations $(\mathrm{r}=0.57-0.92, \mathrm{p}<0.01$; see Online Supplementary Material). We calculated these correlations for the records covering the years 1960-1985, rather than for the entire period of the sclerochronological record, because only during these years were statistically significant correlations found among the 6 live-caught individuals by Kubota et al. (2018a). Among the 10 dead shells, the SGI of eight shells showed a statistically significant correlation with the average of the SGIs of the 6 live-caught individuals only if the last annual increment was produced in 2010; if the date of the last increment was shifted forward or backward by up to 5 years, no statistically significant correlation was found (see Online Supplementary Material). The SGI of 1 dead shell (specimen 110909FKW_ dead_A02R) showed a statistically significant correlation with the master chronology if the last annual increment was produced in $2011(\mathrm{r}=0.45, \mathrm{p}=0.02)$, but the correlation was stronger if the increment was precipitated in $2010 \quad(\mathrm{r}=0.66, \mathrm{p}<0.001)$ (see Online Supplementary Material). The SGI of the 10th dead shell (specimen 160608FKW_dead_ A14R) showed a statistically significant correlation with the average of the SGIs of the 6 live-caught individuals if the date of the last increment was 2015. The master chronology in this study area extended back to 1890, and the expressed population signal (EPS) calculated by the ARSTAN software for the 6 live-caught individuals and the 9 dead shells that most likely died in 2010 was higher than 0.85 during 1960-1985, when the SGI variability was particularly large; this EPS value is generally accepted to indicate an adequate level of correlated variation among populations. This EPS result indicates the existence of shared patterns of variation among individual clams, at least during this time interval (Figure 3).

\section{DISCUSSION}

\section{Timing of Death of $M$. stimpsoni}

The radiocarbon dating results (see Online Supplementary Material) showed that, among the 27 dead shells of $M$. stimpsoni dated in this study, 7 of the clams died in the pre-bomb era and the others died in the post-bomb era. In this study, we focused on the 20 individuals that died in the post-bomb era. Because the dating error for pre-bomb era specimens is as large as 50 years, it is difficult to establish a causal relationship between the time of death and the timing of tsunamis or other environmental events. The ${ }^{14} \mathrm{C}$ value of the last annual increment of these 20 individuals suggests that 10 of them (5 collected in September 2011 and 5 in June 2016) died around 2010. The $\mathrm{F}^{14} \mathrm{C}$ values of the last increments of these 10 dead shells (1.0157-1.0411) are consistent with those of individuals collected alive in 2010, 2012, and 2016 (1.0238-1.0344) (Kubota et al. 2018a). On the other hand, the $\mathrm{F}^{14} \mathrm{C}$ values of the ontogenetically younger portions of these 10 dead shells were $1.0465-1.1184$ (that is, the portion with mean growth years centered on 1965-1981; note that the time-averaging period of each sample was large, up to 16 years, because the slow-growing part of each shell was sampled). These values are in excellent agreement with the expected values based on the bomb- ${ }^{14} \mathrm{C}$ record for Funakoshi Bay (Figure 2a). 


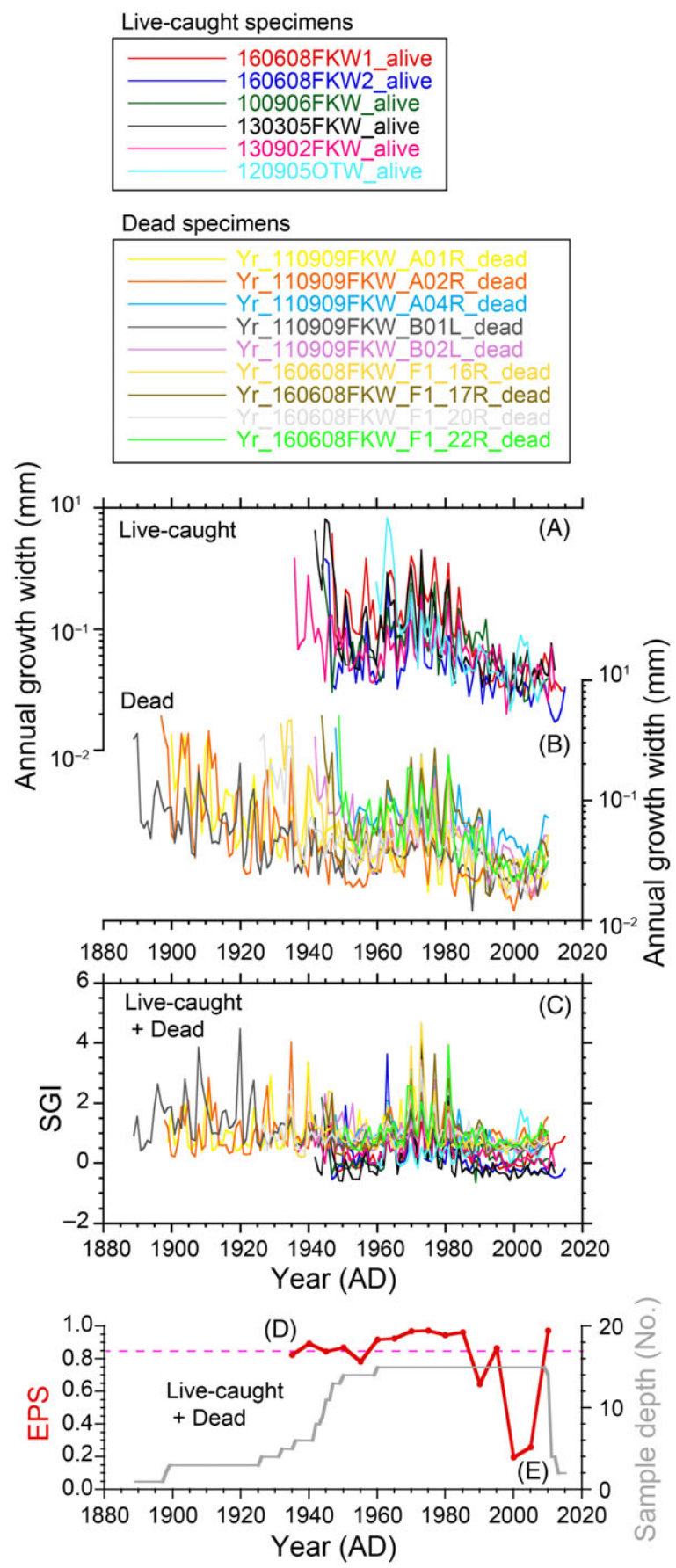

Figure 3 (A, B) Variations in the annual growth increment widths of the 6 live-caught individuals and the 9 shells of clams that were likely killed by the March 2011 tsunami. (C) Standardized growth indices (SGIs) of the 15 live-caught and dead shells. (D, E) Expressed population signal (EPS) (D) and the number of $M$. stimpsoni shells contributing to the reconstruction (sample depth) (E). The pink dashed line represents EPS value of 0.85, which is the EPS value generally accepted to indicate that a statistically significant level of co-variation among populations (see main text). EPS is case sample numbers are less than 5 is not shown here. Note that patterns of SGI variation agree well among individual shells, especially during the years 1960-1985. 


\section{K Kubota et al.}

The widths of the last annual increment can be used to constrain the timing of death with seasonal resolution. The last annual increments of 9 of the 10 individuals described above were as wide as the annual increments of the previous year. Therefore, the possibility that they died (and shell growth ceased) during the summer is low; that is, they died not in summer 2010, but later, after shell growth had ceased. Because the growth period of $M$. stimpsoni in Funakoshi Bay begins in June and continues until the following January, it is likely that these individuals precipitated their last shell increments in 2010, but died in early 2011. Thus, the March 2011 tsunami likely led to the deaths of these individuals. However, radiocarbon dating can only suggest that the specimens died around 2010 because, given the various uncertainties, it is quite difficult to obtain ages with the necessary precision of one year to identify the cause of death. These uncertainties arise from the analytical uncertainty of the radiocarbon measurement, the slight differences in growth period (month) among individuals, the heterogeneity of seawater ${ }^{14} \mathrm{C}$, and the relatively large period of averaging of inner part of the shell required by the sampling technique.

However, by combining bomb- ${ }^{14} \mathrm{C}$ dating with a sclerochronological analysis, age determination with a one-year precision is possible (we selected only relatively long-lived individuals for sclerochronological analysis; thus, we have not been able to determine ages of all of the post-bomb specimens). To sum up the sclerochronological analysis, we found that among ${ }^{14} \mathrm{C}$-dated 10 individuals 9 died in 2010, but 1 (specimen 110909FKW_dead_ A02R) died in 2015.

The $\mathrm{F}^{14} \mathrm{C}$ value of the last increment of 1 individual caught alive in September 2010 (100906FKW_alive) was 1.0344, which is in good agreement with the $\mathrm{F}^{14} \mathrm{C}$ values of 7 of 9 dead shells (1.0304-1.0411) (Figure 2). The $\mathrm{F}^{14} \mathrm{C}$ values of the other 2 dead shells, however, were only 1.0157 and 1.0163 (Figure 2). If only the $\mathrm{F}^{14} \mathrm{C}$ data are taken into account, it would seem that these 2 dead shells precipitated their last annual increment after 2010, because they were collected in 2016 from the seafloor and because there $\mathrm{F}^{14} \mathrm{C}$ values are closer to those of specimens caught alive in 2012 and 2016 (120901OTW_alive and 160608FKW_alive_01R, respectively). However, our sclerochronological analysis revealed that these 2 dead shells also precipitated their last annual increment in $2010(\mathrm{r}=0.81-0.82$, $\mathrm{p}<0.0001$; see Online Supplementary Material). The $\mathrm{F}^{14} \mathrm{C}$ values of the tenth individual inferred by radiocarbon dating alone to have died in 2010 (160608FKW_dead_14R) were 1.0195 for the last annual increment and 1.1035 for increments precipitated when it was ontogenetically younger. However, sclerochronological analysis of this specimen revealed that the last annual increment was precipitated in $2015(\mathrm{r}=0.82, \mathrm{p}<0.0001)$ (see Online Supplementary Material). It is noteworthy that, different from the other 9 individuals inferred to have died in 2010, the last increment of this specimen was only half as wide as the increment of the previous year. Therefore, the shell growth in this individual was interrupted in summer 2015, when the individual died for an unknown reason (the summertime temperature in 2015 was not unusual). In summary, on the basis of ${ }^{14} \mathrm{C}$ data alone, 10 individuals appeared to have died in 2010 , but by combining ${ }^{14} \mathrm{C}$ data with a sclerochronological analysis, it was possible to show that 1 of the 10 died not in 2010 but in 2015 .

From these results, we inferred that the deaths of the 9 individuals (dead shells) that precipitated their last annual increments in 2010 were likely related to the March 2011 tsunami for the following reasons: (1) the $\mathrm{F}^{14} \mathrm{C}$ values of the last increments and of the inner parts of the dead shells coincided well with the bomb- ${ }^{14} \mathrm{C}$ record in the study area; (2) correlations between the average SGI of the live-caught individuals and the SGIs of the 
dead shells in all combinations were statistically significant; and (3) the width of the last increments showed that these animals died, not during the shell growth season, but later, after growth had ceased.

\section{How Might the March 2011 Tsunami Have Caused the M. stimpsoni Deaths?}

We showed that mass mortality in M. stimpsoni ( 9 of 20 individuals that died in the post-bomb era) was likely related to the March 2011 tsunami, but other possible reasons for this mass mortality need to be carefully addressed. In particular, during winter 2010 to spring 2011, water temperature may have become unsuitable or predation by other animals may have increased. With regard to the former, the mean bottom water temperature in March 2011 was $7.05^{\circ} \mathrm{C}, 0.97^{\circ} \mathrm{C}$ higher than the 30 -year climatological mean; therefore, unsuitably high water temperatures probably did not cause death in $M$. stimpsoni, because this clam species can survive and grow (calcify) in water temperatures of up to $\sim 20^{\circ} \mathrm{C}$ in summer. This species is considered to have a wide temperature tolerance because it is distributed over a wide latitudinal range in the northwest Pacific, from temperate to subpolar regions (e.g., off South Korea, Khim et al. 1998; off Hokkaido, northern Japan, Tanabe et al. 2017). This wide temperature tolerance suggests that it is unlikely that unsuitable temperatures were a major cause of death of this clam. With regard to the latter, it is also unlikely that predation by other animals caused mass mortality in this clam for three reasons: (1) $M$. stimpsoni lives beneath the seafloor and is thus inaccessible to many predators; (2) the thick shells of adult individuals protect them from predation; and (3) the shells did not show any damage, such as holes drilled by carnivorous gastropods, or other signs of predation (Nakaoka 2000; Chiba and Sato 2013).

The distribution of tsunami deposits in Funakoshi Bay suggests that the seafloor was first greatly eroded by sub-bottom flows caused by the tsunami and subsequently covered by laminated tsunami deposits (Seike et al. 2017, 2018). Clams that became buried beneath these tsunami deposits might have suffocated because they were unable to escape from deep burial. This possibility is supported by the finding of an articulated dead shell within the tsunami deposits; furthermore, the $\mathrm{F}^{14} \mathrm{C}$ value of the last annual increment of this shell (1.0392) was close to those of specimens caught live during 2010-2016 and also to those of the clams that died in March 2011. However, sclerochronological analysis of this shell was not performed because the shell became broken during the coring (Figure 2). It is also possible that sediment liquefaction caused by ground shaking during the earthquake caused M. stimpsoni individuals to become exposed above the seafloor, because density of this animal is lower than that of the ambient substrate (Seike et al. 2019). Such exposure might lead to the death of individuals that were not able to re-enter the sediment (e.g., by predation by octopus). Although it is clear that the mass mortality of $M$. stimpsoni was related to March 2011 earthquake and tsunami, the specific mechanism of death is difficult to determine. Because we collected dead shells only from the seafloor surface, we do not know whether many dead individuals might remain buried in the tsunami deposits, although wave action associated with, for example, an atmospheric low pressure system might bring some once-buried individuals to the seafloor.

\section{Relationship between M. stimpsoni Deaths and Past Tsunamis}

Although the deaths of at least 9 of the 27 studied individuals collected as dead shells were related to the March 2011 earthquake and tsunami, the other deaths did not coincide with 
the occurrence of a tsunami. Among those clams that died during the post-bomb era, ${ }^{14} \mathrm{C}$ dating and sclerochronological analysis revealed that 2 individuals died in 1966 and 4 others died in 1968, 1971, 1986, and 2015 (Figure 4). Because neither water temperature (high or low) nor the shell growth period (longer or shorter) were unusual in these years, no environmental factor seems to have directly influenced their deaths. Furthermore, it is noteworthy that we found no evidence that the tsunami generated by the 1960 Chilean earthquake that struck northeast Japan in 1960 caused mass mortality of M. stimpsoni (Figure 4). One possible reason is that the amplitude of the 1960 tsunami (maximum runup height along the Japanese coast was $\sim 6 \mathrm{~m}$ ) was not large enough to disturb the seafloor environment and damage the benthic community. It would be worthwhile to test this hypothesis by collecting and dating additional dead shells.

Huge tsunamis strike coastal northeastern Japan at intervals of 50-100 years, so it is possible that past tsunamis similar in scale to the March 2011 tsunami might have caused mass mortality of M. stimpsoni. One huge tsunami occurred in 1933 (Showa Sanriku earthquake: run-up height, $\sim 29 \mathrm{~m}$ ) and another in 1896 (Meiji Sanriku earthquake: run-up height, 38 m). However, it is not possible to link a tsunami occurring during the pre-bomb era with the time of death of $M$. stimpsoni individuals by using only conventional ${ }^{14} \mathrm{C}$ dating. The time of death estimated by conventional ${ }^{14} \mathrm{C}$ dating of the 7 individuals that died during the pre-bomb era overlap with the occurrence times of these two tsunamis (Figure 4), but to confirm this association, it will be necessary to extend the master chronology further back in time.

The oldest clam among the live-caught individuals was 92 years old (Shirai et al. 2018), but one of the dead shells was from an individual that had lived for 135 years (110909FKW_dead_B01R). Therefore, there is a chance that additional long-lived individuals will be found by future field surveys. Intriguingly, the longer-lived individual (and many others) must have survived two huge tsunamis, the Showa Sanriku earthquake tsunami in 1933 and the Meiji Sanriku earthquake tsunami in 1896, only to be killed by the March 2011 tsunami. Without the huge environmental disturbance caused by the tsunami, this animal might have lived even longer. Our findings imply that tsunamis act as a constraint on the longevity of $M$. stimpsoni clams living in this region. It would be worthwhile to test this idea by comparing the longevity of $M$. stimpsoni living in this region with that of this species living in other regions that rarely experience tsunamis.

\section{CONCLUSIONS}

By combining ${ }^{14} \mathrm{C}$ and sclerochronological analyses, we showed that many individuals of the long-lived bivalve M. stimpsoni in Funakoshi Bay died during the huge tsunami that took place in March 2011. Further extension of crossdated annual growth increment records should make it possible to identify past mass mortality events related to tsunamis. In particular, the association of M. stimpsoni deaths with the tsunamis that occurred in 1933 and 1896 should be investigated by the method used here for the March 2011 tsunami. The 1896 tsunami occurred in June, which is during the M. stimpsoni shell growth season; thus, evidence for the tsunami may be recorded in the shell by trace element variations, as Murakami-Sugihara et al. (2019) demonstrated in mussel shells. Trace elements in the shell of an individual that experienced the 1896 tsunami as a juvenile, when its annual shell growth rate was large, might serve as a distinct time marker and chronological constraint. 


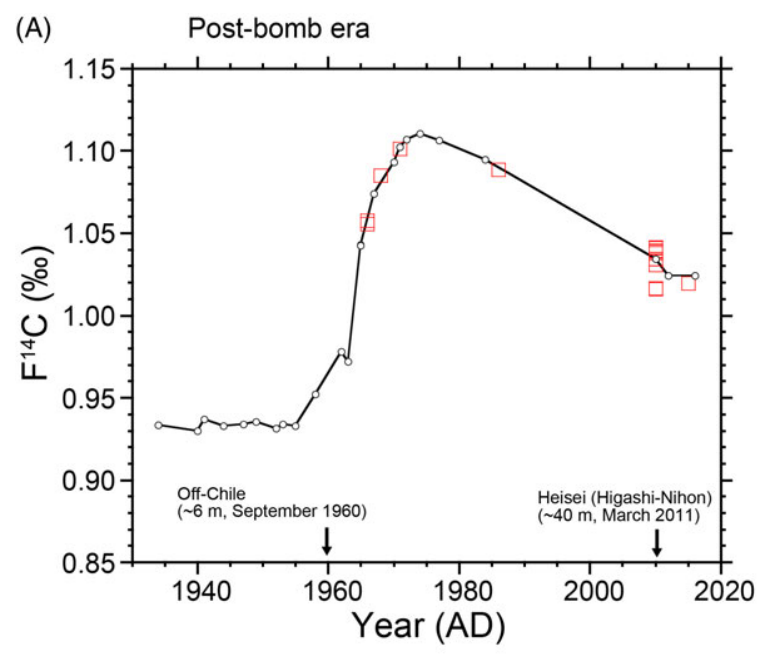

(B)

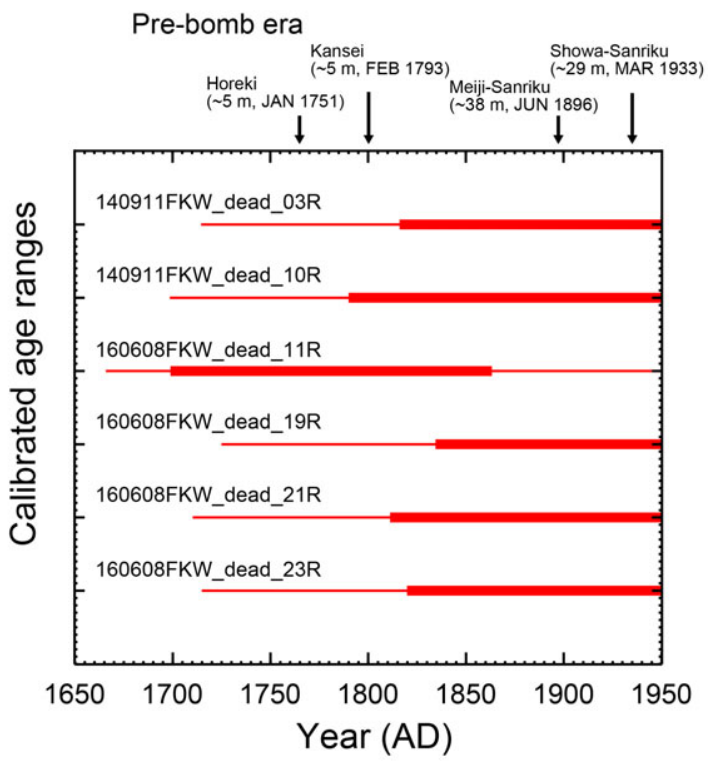

Figure 4 (A) Bomb- ${ }^{14} \mathrm{C}$ record of the study area as in Figure 2 (black line with circles) (Kubota et al. 2018a) and the $\mathrm{F}^{14} \mathrm{C}$ values of the last increment of post-bomb era dead shells collected from the seafloor of Funakoshi Bay (red squares). Black arrows show the dates of major tsunamis that have struck northeastern Japan during the postbomb era. (B) Block plot of the $1 \sigma(68 \%$, thick bars) and $2 \sigma(95 \%$, thin bars $)$ calibrated age ranges for pre-bomb era dead shells collected from Funakoshi Bay, as determined by conventional radiocarbon dating. Black arrows at the top of the panel indicate the dates of major tsunamis that struck northeastern Japan during the pre-bomb era. It is difficult to associate any tsunami with the deaths of $M$. stimpsoni that died during the pre-bomb era because of the relatively large dating errors.

This dating method based on bomb- ${ }^{14} \mathrm{C}$ and sclerochronological analyses of the shells of a long-lived bivalve presented in this study can be applied to the shells of other mollusks that inhabit the Pacific coastal waters of Japan or other oceanic regions affected by tsunamis. However, application of this method to bivalves living in regions where the bomb- ${ }^{14} \mathrm{C}$ peak is dampened (e.g., upwelling and high-latitude ocean regions) would not be effective, nor is it applicable to bivalves that live at abyssal depths, where the amount of bomb-induced ${ }^{14} \mathrm{C}$ 
is too small. Nevertheless, this method may prove effective for understanding the responses of shallow-water bivalve mollusks to environmental disturbances, especially in countries and remote regions where observations of past tsunamis are scarce. Further understanding of such responses may lead to better protection and sustainable use of fishery resources, especially commercially important shellfish.

\section{ACKNOWLEDGMENTS}

We thank T. Goto for cutting the M. stimpsoni shells at the Atmosphere and Ocean Research Institute, and $\mathrm{A}$. Ikeda for the ${ }^{14} \mathrm{C}$ analysis at the Institute for Space-Earth Environmental Research. Our gratitude is also extended to the ship crews of the International Coastal Research Center, the Atmosphere and Ocean Research Institute, and K. Fukuda (Fukuda Kaiyo Kikaku Ltd.) for help with field sampling. Part of the ${ }^{14} \mathrm{C}$ analysis was performed by Paleo Labo Co., Ltd., under a Grant-in-Aid for Young Scientists to K. Kubota. This study was financially supported by Grants-in-Aid for Domestic Research from the Kurita Water and Environment Foundation (grant numbers 16B015 and 17K007) and the Joint Research Program of the Institute for Space-Earth Environmental Research to K. Kubota, Japan Society for the Promotion of Science Kakenhi grants (numbers JP13401521, JP16781047, and JP15647913/H05823) to K. Shirai, the cooperative research program of the Center for Advanced Marine Core Research, Kochi University (number 14B024) to K. Seike, and the research program "Tohoku Ecosystem-Associated Marine Sciences" of the Ministry of Education, Culture, Sports, Science and Technology. All data used are listed in the tables. Finally, we are grateful to the two anonymous reviewers, whose comments substantially improved this manuscript.

\section{SUPPLEMENTARY MATERIAL}

To view supplementary material for this article, please visit https://doi.org/10.1017/RDC. 2021.98

\section{REFERENCES}

Andrews AH, Asami R, Iryu Y, Kobayashi DR, Camacho F. 2016. Bomb-produced radiocarbon in the western tropical Pacific Ocean: Guam coral reveals operation-specific signals from the Pacific Proving Grounds. JGR: Oceans 121: 6351-6366.

Alves EQ, Macario K, Ascough P, Bronk-Ramsey C. 2018. The worldwide marine radiocarbon reservoir effect: definitions, mechanisms, and prospects. Reviews of Geophysics 56:278-305.

Black BA, Griffin D, van der Sleen P, Wanamaker AD Jr, Speer JH, Frank DC, Stahle DW, Pederson N, Copenheaver CA, Trouet V, et al. 2016. The value of crossdating to retain highfrequency variability, climate signals, and extreme events in environmental proxies. Global Change Biology 22:2582-2595.

Bromley RG. 1996. Trace fossils-biology, taphonomy and applications. London: Chapman \& Hall.

Butler PG, Richardson CA, Scourse JD, Witbaard R, Schone BR, Fraser NM, Wanamaker AD Jr,
Bryant CL, Harris I, Robertson I. 2009a. Accurate increment identification and the spatial extent of the common signal in five Arctica islandica chronologies from the Fladen Ground, northern North Sea. Paleoceanography 24:PA2210.

Butler PG, Scourse JD, Richardson CA, Wanamaker AD Jr, Bryant CL, Bennell, JD. 2009b. Continuous marine radiocarbon reservoir calibration and the ${ }^{13} \mathrm{C}$ Suess effect in the Irish Sea: results from the first multi-centennial shellbased marine master chronology. Earth and Planetary Science Letters 279:230-241.

Campana SE, Natanson LJ, Myklevoll S. 2002. Bomb dating and age determination of large pelagic sharks. Canadian Journal of Fisheries and Aquatic Sciences 59:450-455.

Chiba T, Sato S. 2013. Invasion of Laguncula pulchella (Gastropoda: Naticidae) and predatorprey interactions with bivalves on the Tona coast, Miyagi prefecture, northern Japan. Biological Invasions 15:587-598. 
Druffel ERM. 2002. Radiocarbon in corals: records of the carbon cycle, surface circulation and climate. Oceanography 15:122-127.

Fallon SJ, Guilderson TP. 2008. Surface water processes in the Indonesian throughflow as documented by high resolution coral $\mathrm{D}^{14} \mathrm{C}$. Journal of Geophysical Research 113:C09001.

Glynn D, Druffel E, Griffin S, Dunbar R, Osborne M, Sanchez-Cabeza JA. 2013. Early bomb radiocarbon detected in Palau Archipelago corals. Radiocarbon 55:1659-1664.

Grottoli AG, Eakin CM. 2007. A review of modern coral $\delta^{18} \mathrm{O}$ and $\Delta^{14} \mathrm{C}$ proxy records. EarthScience Reviews 81:67-91.

Habe T. 1977. Systematics of mollusca in Japan. Tokyo: Hokuryukan Book Co.

Hamady LL, Natanson LJ, Skomal GB, Thorrold SR. 2014. Vertebral bomb radiocarbon suggests extreme longevity in white sharks. PLoS One 9: e84006.

Hammer S, Levin I. 2017. Monthly mean atmospheric $\mathrm{D}^{14} \mathrm{CO} 2$ at Jungfraujoch and Schauinsland from 1986 to 2016 (heiDATA Dataverse V2) [data accessed 28 Sep 2017]. Available from https://doi.org/10.11588/data/ 10100.

Harris PT. 2014. Shelf and deep-sea sedimentary environments and physical benthic disturbance regimes: a review and synthesis. Marine Geology 353:169-184.

Heaton TJ, Köhler P, Butzin M, Bard E, Reimer RW, Austin WEN, Bronk-Ramsey C, Grootes PM, Hughen KA, Kromer B, Reimer PJ, Adkins J, Burke A, Cook MS, Olsen J, Skinner LC. 2020. Marine20-the marine radiocarbon age calibration curve $(0-55,000$ cal BP). Radiocarbon 62:779-820.

Hirabayashi S, Yokoyama Y, Suzuki A, Miyairi Y, Aze T. 2017. Multidecadal oceanographic changes in the western Pacific detected through high-resolution bomb-derived radiocarbon measurements on corals. Geochemistry, Geophysics, Geosystems 18:1608-1617.

Hua Q, Barbetti M, Rakowski AZ. 2013. Atmospheric radiocarbon for the period 19502010. Radiocarbon 55:2059-2072.

Ide S, Baltay A, Beroza GC. 2011. Shallow dynamic overshoot and energetic deep rupture in the 2011 Mw 9.0 Tohoku-Oki Earthquake. Science 332:1426-1429.

Ishimura D, Yamada K. 2019. Palaeo-tsunami inundation distances deduced from roundness of gravel particles in tsunami deposits. Scientific Reports 9:10251.

Jaramillo E, Dugan JE, Hubbard DM, Melnick D, Manzano M, Duarte C, Campos C, Sanchez R. 2012. Ecological implications of extreme events: footprints of the 2010 earthquake along the Chilean coast. PLoS One 7:e35348.

Jones DS, Arthur MA, Allard DJ. 1989. Sclerochronological records of temperature and growth from shells of Mercenaria mercenaria from Narragansett Bay, Rhode Island. Marine Biology 102:225-234.

Kalish JM. 1993. Pre- and post-bomb radiocarbon in fish otoliths. Earth and Planetary Science Letters 114:549-54.

Khim BK, Je JG, Han SJ, Woo KS, Park YA. 1998. Oxygen isotope profile and age determination of Venus clam Mercenaria stimpsoni (Bivalvia: Veneridae) from the East Sea. Korean Journal of Malacology 14:9-17.

Konishi K, Tanaka T, Sakanoue M. 1981. Secular variation of radiocarbon concentration in seawater: Sclerochronological approach. In: Gomez ED, Birkeland CE, Buddemeier RW, Johannes RE, Marsh JA Jr, Tsuda RT, editors. Proceedings of the Fourth International Coral Reef Symposium 1:181-185.

Kranz PM. 1974. The anastrophic burial of bivalves and its paleoecological significance. The Journal of Geology 82:237-265.

Kubota K, Shirai K, Murakami-Sugihara N, Seike K, Hori M, Tanabe K. 2017. Annual shell growth pattern of the Stimpson's hard clam Mercenaria stimpsoni as revealed by sclerochronological and oxygen stable isotope measurements. Palaeogeography, Palaeoclimatology, Palaeoecology 465:307-315.

Kubota K, Shirai K, Murakami-Sugihara N, Seike K, Tanabe K, Minami M, Nakamura T. 2018a. Bomb- ${ }^{14} \mathrm{C}$ Peak in the North Pacific Recorded in Long-lived Bivalve Shells (Mercenaria stimpsoni). JGR: Oceans 123:2867-2881.

Kubota K, Shirai K, Higuchi T, Miyajima T. 2018 b. Oxygen and hydrogen isotope characteristics of seawater in Otsuchi Bay and meteoric water of inflowing rivers. Coastal Marine Science 41:1-6.

Kubota K, Yokoyama Y, Ishikawa T, Suzuki A. 2015a. A new method for calibrating a boron isotope paleo-pH proxy using massive Porites corals. Geochemistry, Geophysics, Geosystems 16:3333-3342.

Kubota K, Yokoyama Y, Kawakubo Y, Seki A, Sakai S, Ajithprasad P, Maemoku H, Osada T, Bhattacharya SK. 2015b. Migration history of an ariid Indian catfish reconstructed by otolith $\mathrm{Sr} / \mathrm{Ca}$ and $\delta^{18} \mathrm{O}$ micro-analysis. Geochemical Journal 49:469-480

López RA, Penchaszadeh PE, Marcomini SC. 2008. Storm-related strandings of mollusks on the northeast coast of Buenos Aires, Argentina. Journal of Coastal Research 24:925-935.

Mahadevan A. 2001. An analysis of bomb radiocarbon trends in the Pacific. Marine Chemistry 73:273-290.

Mori N, Takahashi T, Yasuda T, Yanagisawa $\mathrm{H}$. 2011. Survey of 2011 Tohoku Earthquake tsunami inundation and run-up. Geophysical Research Letters 38:L00G14.

Murakami-Sugihara N, Shirai K, Hori M, Amano Y, Fukuda H, Obata H, Tanaka K, Mizukawa K, 
Sano Y, Takada H, et al. 2019. Mussel shell geochemical analyses reflect coastal environmental changes following the 2011 Tohoku tsunami. ACS Earth Space Chem. 3:1346-1352.

Nakaoka M. 2000 Nonlethal effects of predators on prey populations: predator-mediated change in bivalve growth. Ecology 81:1031-1045.

Nielsen J, Hedeholm PB, Heinemeier J, Bushnell PG, Christiansen JS, Olsen J, Bronk Ramsey C, Brill RW, Simon M, Steffensen KF, et al. 2016. Eye lens radiocarbon reveals centuries of longevity in the Greenland shark (Somniosus microcephalus). Science 353:702-704.

Sakamoto T, Komatsu K, Yoneda M, Ishimura T, Higuchi T, Shirai K, Kamimura Y, Watanabe C, Kawabata A. 2017. Temperature dependence of $\delta^{18} \mathrm{O}$ in otolith of juvenile Japanese sardine: laboratory rearing experiment with micro-scale analysis. Fisheries Research 194:55-59.

Scourse JD, Wanamaker Jr. AD, Weidman C, Heinemeier J, Reimer PJ, Butler PG, Witbaard R, Richardson CA. 2012. The marine radiocarbon bomb pulse across the temperate North Atlantic: a compilation of $\Delta^{14} \mathrm{C}$ time histories from Arctica islandica growth increments. Radiocarbon 54:165-186.

Seike K, Kitahashi T, Noguchi T. 2016. Sedimentary features of Onagawa Bay, northeastern Japan after the 2011 off the Pacific coast of Tohoku Earthquake: sediment mixing by recolonized benthic animals decreases the preservation potential of tsunami deposits. Journal of Oceanography 72:141-149.

Seike K, Sassa S, Shirai K, Kubota K. 2018. Lasting impact of a tsunami event on sediment-organism interactions in the ocean. JGR: Oceans 123: 1376-1392.

Seike K, Sassa S, Shirai K, Kubota K. 2019. Fate of benthic invertebrates during seabed liquefaction: quantitative comparison of living organism body density with liquefied substrate density. Estuarine Coastal and Shelf Science 223:1-5.

Seike K, Shirai K, Kogure Y. 2013. Disturbance of shallow marine soft-bottom environments and megabenthos assemblages by a huge tsunami induced by the 2011 M9.0 Tohoku-Oki earthquake. PLoS One 8:e65417.

Seike K, Shirai K, Kubota K. 2017. Population dynamics of megabenthic invertebrates in Funakoshi Bay, Iwate Prefecture, northeastern Japan: 6 years' field observation after the 2011 tsunami disaster. Nippon Suisan Gakkaishi 83:668-671. In Japanese.

Shirai K, Kubota K, Murakami-Sugihara N, Seike K, Hakozaki M, Tanabe K. 2018. Stimpson's hard clam Mercenaria stimpsoni, a century-long climate recorder for the northwest Pacific coast. Mar. Environ. Res. 133:49-56.

Tanabe K, Mimura T, Miyaji T, Shirai K, Kubota K, Murakami-Sugihara K, Schone BR. 2017. Interannual to decadal variability of summer sea surface temperature in the Sea of Okhotsk recorded in the shell growth history of Stimpson's hard clams (Mercenaria stimpsoni). Global and Planetary Change 157:35-47.

Tanaka K, Komatsu K, Itoh S, Yanagimoto D, Ishizu M, Hasumi H, Sakamoto TT, Urakawa S, Michida Y. 2017. Baroclinic circulation and its high frequency variability in Otsuchi Bay on the Sanriku ria coast, Japan. Journal of Oceanography 73:25-28.

Toggweiler JR, Druffel ER, Key RM, Galbraith ED. 2019. Upwelling in the ocean basins north of the ACC: 1 . On the upwelling exposed by the surface distribution of $\Delta^{14}$ C. JGR: Oceans 124:2591-2608.

Wigley TML, Briffa KR, Jones PD. 1984. On the average value of correlated time series, with applications in dendroclimatology and hydrometeorology. Journal of Applied Meteorology and Climatology 23:201-213. 